\title{
Research on the Restrictive Factors and Countermeasures of Transformation of Science Technology Achievements in Chi- na's Agricultural Universities
}

\author{
Chen Zhiying ${ }^{1}$ Sha Chunyu Dun Chengyuan \\ College of Economics and Management, Northeast Agricultural Universi- \\ ty, Harbin, China, 150030
}

\begin{abstract}
The transformation ratio of sci-tech achievements of agricultural universities was low in China. In this paper the restrictive factors of transformation of achievements were analyzed, and some countermeasures that will promote the transformation of achievements was put forward, including of improving the laws and regulations of achievement transformation, updating the concept, promoting the innovation of system and mechanism, establishing the marketoriented mechanism of transformation, strengthening the construction of the talent team of the sci-tech achievement transformation and increasing the input to the achievement transformation and so on.
\end{abstract}

Keywords: agricultural university; transformation of science and technology achievement; mechanism

\section{Preface}

In China agricultural university is not only an important birthplace of the agri- cultural sci-tech achievements, but also an important support of the transformation of agricultural sci-tech achievement. However, most of achievements of agricultural universities were not translated into the productive forces so that the idle and waste of the sci-tech achievements were very serious. Because of the long-term control of the planned economy and the effect of the concept, capital and mechanism, the effective transformation mechanism has not been yet formed. So many practical scitech achievements were still in the form of knowledge. The agricultural development in China mainly depends on the progress of science and technology. The application rate of the sci-tech achievements in agriculture in China was far less than the developed countries. At present, the transformation rate of agricultural sci-tech achievements was only $30 \% \sim 40 \%$ in China, 50\% 60\% in British, France and Germany, and $80 \%$ in Ameri$\mathrm{ca}^{[1]}$. In China at the new stage of agricultural development how to solve the contradiction between population growth and land reduction and to achieve the agricultural modernization had become a

\footnotetext{
${ }^{1}$ Corresponding Author: Chen Zhiying.

Funded Projects: National Science and Technology Projects in Rural Areas during "Twelfth Five Year" (2013BAD20B04); Science and Technology Research Program in Heilongjiang Province (GZ11D206).
} 
pressing matter. Therefore, the research on the restrictive factors and countermeasures of sci-tech achievements transformation of China's agricultural universities has an important significance to strengthen the transformation of the scitech achievements of agricultural universities.

\section{Restrictive factors of the sci-tech achievements transformation of the agricultural universities in China}

The annual transformation rate of scitech achievements was low in China's agricultural universities. A lot of achievements had not been translated into the practical productive forces. In agricultural universities the factors restricting the transformation of achievement are as follows:

\subsection{Less of an emphasis on the trans- formation of achievements}

The teaching, scientific research and social service are the basic duties of the agricultural universities. So the sci-tech achievement transformation should be the one of the agricultural universities duties ${ }^{[2]}$. However, the government did not pay enough attention on the achievement transformation of agricultural universities. In the economic and social development plans of government the achievement transformation was not an important factor in promoting social development. The administrative departments of science and education did not take strengthening the sci-tech innovation, accelerating the achievements transformation and industrialization of the high-tech as the duties of universities.

In addition, the recognition of the management departments and research staff of agricultural universities to the transformation of achievements had an obvious deviation. In agricultural univer- sities the number of published papers in the publication and the achievements awards were put much emphasis while the transformation of achievements was ignored. The management work of scientific research was limited on the establish-

ment, examination and approval, inspecti on, assessment, identification, inspection and appraisal of research projects. The industrialization and transformation of achievements were not considered basically. The researchers usually regarded the research work as the single knowledge. Their research work was mainly to publish papers, evaluate achievements and declare patents. Their research projects can not meet the market needs. The small part of their achievements was extended, applied and generated the economic benefits.

\subsection{Traditional mechanism of the sci- entific research}

There is a direct relationship between the transformation of scitech achievements and the transformation mechanism, technology system and economic system. In some ways, the current mechanism did not adapt to the scitech achievement transformation of agricultural universities. First, China's socialist market economic system was not perfect; the sci-tech innovation system had not been yet formed fully; the development and application of technologies were not been connected. Secondly, on the operation mechanism of agricultural universities there were many problems, for examples, the imperfect policy system, the lack of flexibility which adapt to the market changes; the unreasonable distribution of interests; policy bias and the lack of the achievement extension team of high quality and so on. In addition, within agricultural universities there were not the industry-university-research entities that concentrated the basic research, the ap- 
plied research and the industrial development, and there was not the mechanism of the achievement industrialization.

\subsection{Defects of the agricultural sci- tech achievements}

In agricultural universities immaturity of some sci-tech achievements was one of the defects of the achievements. It was as follows: the lack of progressiveness; low technology maturity; the low reliability; the lack of the supporting equipment and technologies for the further development. So the conditions of sci-tech achievement transformation were not mature enough. The level of the technologies was low, and they were still remained at the experimental stage so that it was difficult to make them transform to be the achievements that can produce the realistic productivity. Disconnection of the sci-tech achievements of agricultural universities and the market demands was the other defect of sci-tech achievements. The potential market demand of agricultural production is a prerequisite for the transformation of achievements. However, in the research work of agricultural universities only the formation of scientific research was thought highly; the market needs were not paid attention; and the application and popularization of achievements were ignored.

\subsection{Ignorance of talent team con- struction of agricultural sci-tech achievement transformation}

In agricultural universities the department of scientific research management should be mainly responsible for the scientific research management, the achievement extension and the social service work. But the management of scitech achievements in the most agricultural universities only included mainly the statistics and award process of achievements. The traditional mode of technology extension was used in the agricultural sci-tech achievement trans- formation, for example, travelling from village to village, giving oral instruction and face to face teaching and so on ${ }^{[3]}$.

To play the advantage of sci-tech research of universities needs the creative and compound talents of the sci-tech popularization that understand the professional knowledge, are good at business and management. Because the achievement transformation is a technical, economic and service demanding job we must make technology assessment, a full market prediction, and analysis of investment benefit to technology transformation if we want to complete this work. And these works cannot be done without a strong and compound talent team of the achievement popularization. At present, because of the effect of the personnel staff, in most agricultural universities the talent team of the achievement transformation had not been established so that the transformation of achievements was affected and the most identified research results can not be transformed into the productive force. According to the study, much foreign universities had a technology transfer office, such as in America's all research universities the various institutions of the technology transfer were almost set up $^{[4]}$.

\subsection{Serious shortage of funds}

In China agricultural universities faced a serious funding challenge of the scientific research and achievement transformation.

First, the input of the government to the scientific research of agricultural universities was relatively weak. In 2012, the R\&D fund of agricultural universities only was $7.6 \%$ of the total, which only was the half level of the independent institutions of scientific research. And in recent years this ratio was still decreasing. In the most developed countries it 
was more than $10 \%$; even more than $20 \%$ in some countries. In 2009 it was $19 \%$ and $12.5 \%$ respectively in America and Japan ${ }^{[5]}$ Secondly, because innovation capability of enterprise was increasing gradually the enterprise reduced relatively the investment to the research of agricultural university. Thirdly, on the extension of university achievements the fund of the government was insufficiency. The ratio of investment of scientific research and extension in China was only $0.2 \%$ of the total output of the national economy, while was $0.7 \%$ in India, and was $2 \%$ to $3 \%$ in the developed countries. At present the research fund of agricultural university was scarce, and the fund of achievement extension was scarcer so that it was difficult to support the application of the achievements.

\section{Countermeasures promoting the achievement transformation in agricultural universities}

In 2002, the Opinion on Giving Full Play to the Role of Sci-tech Innovation of the Higher Schools was issued jointly by the State Ministry of Sci-tech and the Ministry of Education. In the Opinion the rights and interests of the sci-tech personnel were protected, and the motivation of the technology innovation and achievement transformation were inspired. However, to promote the transformation of sci-tech achievement in agricultural universities some countermeasures should be taken.

\subsection{Improving laws and policies of the achievement transformation}

The improvement of the series of policies and laws of agriculture sci-tech achievement transformation will arouse enormously the initiative of all sectors of society, and will strengthen the support and protection to the transformation of achievements. In China the most fundamental problem in transformation of achievements was still the imperfect management mechanism. Although the sci-tech Achievement Transformation Laws, the Agriculture Extension Law, the Intellectual Property Rights Protection Law and other laws and regulations had been introduced, in these laws and regulations the specific characteristics of the sci-tech achievements of agricultural universities were not been thought about, and their operability was not strong so as not to mobilize the enthusiasm of staff engaging in the sci-tech achievement transformation under the condition of market economy. The government should further strengthen the support and protection of the policies to achievement transformation.

\subsection{Updating the concept of the achievement transformation}

The achievement transformation involves in many factors. The renewal of concepts plays a decisive role. First, the social functions of agricultural university should be recognized again. Now agricultural university is not only the teaching place, but also an important education and scientific research center and an important force of knowledge innovation and achievement transformation. Therefore, we must make the agricultural universities become the base of training senior specialists in agriculture and developing agricultural scitech and the incubator diffusing agricultural high-tech to society and transforming the agricultural high-tech. Secondly, in agricultural universities the achievement transformation should be played an important role. We should make the performance of the achievement transformation become the condition of prizes and evaluation of professional titles of agricultural universities, and establish the reasonable and practicable standard adjusting the distribution ratio of 
interest of achievement transformation so as to tend properly to the personnel promoting achievements transformation.

\subsection{Promoting the system and mech- anism innovation of achievement transformation}

First, the reform of the agricultural scitech system should be deepened. The introduction of competition mechanism will promote the technology power of agricultural university into the enterprise so that at present the situation that in most of agricultural universities the sci-tech strength was divorced from the enterprises and the market will be changed. Secondly, the incentive mechanism helping the achievement transformation of agricultural universities should be established. Establishment of the reward system on the achievement transformation will fully mobilize and encourage all forces to promote the transformation. Thirdly, in agricultural universities the reform of the internal system and personnel system of scientific research should be deepened so as to make the transformation of achievements form a virtuous circle. On the scientific research system, the professional teachers and technical staff will set a series of technical companies or development centers, and they can also establish the research and development institutions to transform achievements and develop new products by combining with the research institutes or enterprises. On the personnel system, teachers should be evaluated according of categories. The ones which carry out the transformation of sci-tech achievements should be given the corresponding support on policies.

\subsection{Establishing market-oriented conversion mechanism}

First, based on the market the mechanism of technical establishment project should be established. According to the needs of the economic construction and social development, namely the market need, the topics of research projects are chose. This is the starting point and destination of the achievement transformation under the market economy, and it is the key if the achievements can be transformed into the actual productivity. Secondly, a market-oriented concept should be established to overcome the single technology view. The market-oriented agricultural research should be that in the choice of scientific research project topic the market opportunities should been seized, and the new technologies and new products should be timely developed to meet continuously the needs of the social production and life.

\subsection{Strengthening the construction of talent team of achievement trans- formation}

Establishing the evaluation system of sci-tech personnel, which aimed at the achievement transformation, will guide them to pay attention to the achievement transformation. Firstly, in agricultural universities a certain amount of jobs of sci-tech development and achievement transformation should be set up just like teachers and research job. Secondly, in agricultural universities the technical post title index of the development and transformation of achievements should be established, and the professional title evaluation standard should be formulated to solve their concern and apprehension of teachers engaging in development and transformation. Finally, the corresponding distribution policies should be made to encourage staff active of development and transformation of technologies and give them a reward in the transformation so that all kinds of personnel were attracted by the favorable treatment to be engaged in the development and transformation. 


\subsection{Increasing the input of the achievement transformation}

The serious shortage of funds is one of the key factors affecting on the sci-tech achievement transformation.

Firstly, the input of the government finance departments at all levels to the achievement transformation should be increased, and the ratio of investment to the research and development should be allocated reasonably. It should not be less than $1 \%$ of the government revenues, and should be improved greatly on the existing basis. While the government increases the investment of the achievement transformation the use efficiency of funds should be improved especially. Secondly, the financing channels should be expanded, and a diversified investment and financing system should be established. Besides the sci-tech loan of banks and the financial technology investment, the government should encourage and support the agricultural universities and enterprises to raise funds for digestion and innovation of the local major achievements in engineering and major technology introduction facing the market. Thirdly, the government should support and encourage the risk investment of transformation of achievements to create a good legal environment for venture investors. To change the status of single source channels of technology risk capital the venture capital market of sci-tech should be opened, and policies encouraging foreign investment and private capital to put into venture capital should be developed to expanse rapidly the scale of venture capital in China. In addition, the increase of enterprises input to agricultural universities should be encouraged and supported.

\section{Epilogue}

The transformation of achievements of agricultural university is a complicated engineering. By deepening continuously the reform, innovating boldly and mobilizing all aspects of enthusiasm the road of achievement transformation that suits the agricultural universities in China can be formed gradually; the in-depth development of the achievement transformation can be promoted; in China the realization of agricultural modernization can be accelerated.

\section{Reference}

[1] J. Yang, X. Fu, H. Xiao, Relying on Sci-tech Progress to Increase the Income of the Farmers in the Western Region, Economy of Agricultural Technology, pp.43-45, 2001 (4).

[2] J. Gan, L. Zeng, X. Zhou, The Bottleneck and Countermeasures of the Transformation of Sci-tech Achievements, Silicon Valley, pp.104-105, 2008 (17).

[3] Z. Yang et al, Analysis of Factors Affecting the Transformation of Agricultural Sci-tech Achievements in Agricultural Universities, Agricultural Scitech Management, pp. 67-69, 2012,31 (3).

[4] M. Wang, Analysis of Key Factors of Efficient Operation of Technology Licensing Office in American University and the Policy Implications for China, The Progress of Sci-tech, pp. 35-40, 2010, 27 (12).

[5] Http://caing.zjol.com.cn/ 2013-0927/100586797.html,2013-09-27 